\title{
Can the addition of biochar improve the performance of biogas digesters operated at $45^{\circ} \mathrm{C}$ ?
}

\author{
Samson Oluwasegun Masebinu ${ }^{1^{*}}$, Olufunto Tolulope Fanoro ${ }^{2}$, Heribert Insam ${ }^{3}$, Charles Mbohwa \\ Andreas Otto Wagner ${ }^{3}$, Rudolf Markt ${ }^{3}$, Sebastian Hupfauf ${ }^{3^{* \dagger}}$ \\ ${ }^{1}$ Process, Energy and Environmental Technology Station, University of Johannesburg, South Africa \\ ${ }^{2}$ Biotechnology Department, University of Johannesburg, South Africa \\ ${ }^{3}$ Department of Microbiology, University of Innsbruck, Austria \\ ${ }^{4}$ Operations and Engineering Management, University of Johannesburg, South Africa \\ "These authors contributed equally to this work.
}

\begin{abstract}
Biogas from anaerobic digestion (AD) may contribute towards a green energy scene in the future. Despite many benefits, $A D$ plant operators are still challenged by limitations of the technology. This study aimed at evaluating the effect of biochar addition to AD reactors operated at $45^{\circ} \mathrm{C}$ to optimize productivity, efficiency and stability of the process. Biochar is characterized by a large surface area and may therefore facilitate the creation of biofilms on the one hand and remove environmental contaminants on the other hand. Moreover, biochar may serve as pH control agent due to its alkaline properties, counteracting reactor acidification. Our results showed that the addition of biochar reduced efficiently the amount of $\mathrm{H}_{2} \mathrm{~S}$ that initially occurred in the headspace during reactor start-up. Nevertheless, no impact on biogas- and methane yields was observed. This might be explained with an already well-working AD system without any severe disturbances, where the balancing nature of biochar did hardly count. Future studies, however, need to evaluate the effect on stressed systems. The microbiome analysis provided a detailed view of the microbial dynamics during the start-up phase, revealing Methanosarcina as dominant methanogen in the end. The addition of biochar did not alter the microbial community composition.
\end{abstract}

Keywords: Anaerobic digestion, AD, Process optimisation, Methane, methanogens, $16 \mathrm{~S}$ rRNA

\section{Introduction}

Anaerobic digestion (AD) is an established management and energy extraction technology for organic wastes and purpose-grown energy crops of various types under anoxic conditions by consortia of microorganisms to produce biogas [1, 2]. Although $\mathrm{AD}$ offers many benefits, the process presents some limitations as commercial $\mathrm{AD}$ plants typically operate below optimal performance levels [3, 4]. The limitations of $\mathrm{AD}$ can be broadly categorised into three groups: (1) the restriction on substrate types fed to the digester without pre-treatment, (2) process and product quality assurance, and (3) management of process effluents and emissions [5-10]. The preference of $\mathrm{AD}$ for wet organic waste requires that lignocellulose-rich agricultural biomass is pre-treated if high biogas yield is expected without sacrificing digester volume. This pre-treatment adds to the energy demand and can introduce inhibitors, leading to $\mathrm{AD}$ instability. The produced biogas requires further treatment before it can be used in all other applications aside from combustion. High specific volume, low pressure and low relative density characterise biogas obtained from an $\mathrm{AD}$ process. These undesirable characteristics with a high proportion of non-combustible carbon dioxide makes biogas unsuitable for energy storage. According to Budzianowski et al. [11], reduction in $\mathrm{CO}_{2}$ concentration in biogas will reduce the required resources and scale of biogas upgrading systems.

Various attempts to improve the $\mathrm{AD}$ process stability and product quality have been made. Approaches such as biological, chemical, physical, mechanical, thermal and ultrasound techniques have been
This is an Open Access article distributed under the terms of the Creative Commons Attribution Non-Commercial License (http://creativecommons.org/licenses/by-nc/3.0/) which permits unrestricted non-commercial use, distribution, and reproduction in any medium, provided the original work is properly cited.

Copyright (C) 2022 Korean Society of Environmental Engineers
Received November 24, 2020 Accepted January 28, 2021

${ }^{\dagger}$ Corresponding author

E-mail: Sebastian.Hupfauf@uibk.ac.at

Tel: +4351250751326 Fax: +43512507 2928

ORCID: 0000-0002-2012-9966 
implemented [12-16]. More recently, bio-inspired materials have been investigated for their potential to facilitate microbial community clustering, and manage some of the indicators for process stability in $\mathrm{AD}$. Among the varieties of bio-inspired materials is biochar produced from the thermal decomposition of biomass in the absence of oxygen (pyrolysis). Biochar is a cost-effective material and an environmentally friendly approach for the production of carbon-based adsorbent with properties similar to activated carbon [17-19]. Carbon-based materials such as graphite and activated carbon have been considered to stabilise the $\mathrm{AD}$ process and increase the biogas yield $[8,20]$, but the production process of commercial-grade activated carbon is limited due to environmental-, healthand safety concerns [21]. This challenge is not a limitation for bio-inspired materials during biochar production and the subsequent in-situ application for $\mathrm{AD}$ as biochar has long been applied to soil for carbon sequestration. Biochar has the potential to effectively remove both organic and inorganic environmental contaminants as well as $\mathrm{CO}_{2}$ from biogas due to its high surface area, stable structure, porosity, high ion exchange capacity and the presence of various surface functional groups (e.g. $-\mathrm{OH},-\mathrm{COOH}, \mathrm{C}-\mathrm{O}$, $\mathrm{O}=\mathrm{C}=\mathrm{O}$ ) [19]. An exhaustive review of the characteristics of biochar for $\mathrm{AD}$ and recent applications to $\mathrm{AD}$ has been presented by Masebinu et al. [10]. In the $\mathrm{AD}$ process, biochar has been applied mostly for $\mathrm{pH}$ control due to its alkaline nature, biofilm formation due to the porous structure and large surface area and for toxic compound inhibition [18, 22, 23]. Chen et al. [24] reported the ability of biochar to adsorb $\mathrm{NH}_{3}$ in $\mathrm{AD}$ while its role in volatile fatty acid (VFA) management and $\mathrm{CH}_{4}$ production was investigated by Sunyoto et al. [25]. In AD, biochar selectivity towards certain groups of parameters, however, cannot be controlled. Mumme et al. [26] reported that biochar likewise adsorbed inhibitors, nutrients and useful metabolites. Therefore, uncontrolled addition of biochar to $\mathrm{AD}$ can result in a negative interaction with the process. In a recent investigation, Shao et al. [27] concluded that biochar effectiveness is limited to stressed $\mathrm{AD}$ processes and its effect on well-buffered systems is insignificant.

Among the observed parameters for the performance of biochar in $\mathrm{AD}$ is the operating temperature. The effectiveness of biochar tends to be higher in $\mathrm{AD}$ systems operated thermophilically $\left(50-60^{\circ} \mathrm{C}\right)$. Elevated temperature offers higher metabolic rates, better pathogen inactivation, increased biogas- and $\mathrm{CH}_{4}$ yields, as well as reduced foaming [1, 28, 29]. The high temperature can also accelerate leaching and dissolution of alkali metal cations from biochar, which improves the digestibility of substrate and endothermic adsorption of biochar [30-32]. Though the merits of thermophilic digestion are well outlined in the literature, yet the process requires intensive monitoring and microbes are very sensitive to fluctuation in operating temperature. $\mathrm{AD}$ at mesophilic temperature $\left(30-40^{\circ} \mathrm{C}\right)$ is generally considered more stable, less sensitive to inhibitory components and lowers the inhibitory effects of long chain fatty acid [33] and ammonium. Moreover, it is characterized by a lower endogenous thermal energy demand [34, 35] and shows a significantly higher dewatering potential of the digestate [36], which is crucial since digestate handling is a major cost factor in an industrial-scale biogas facility. For these reasons, many biogas plants operate at mesophilic temperature. However, Hupfauf et al. [4], Tian et al. [37] and Hupfauf et al. [38] highlighted that the general acceptable temperature for mesophilic digestion at $37^{\circ} \mathrm{C}$ is not optimal due to a low substrate conversion rate and insufficient hygienisation. Instead, a preferable process temperature of $45^{\circ} \mathrm{C}$ was proposed by the authors that would combine the advantages of both, thermo- and mesophilic operation, accompanied by a promotion of members of the phylum Firmicutes with their superior capabilities to produce methanogenic precursors. The results of Hupfauf et al. [38] further indicated that higher organic loading rates might be tolerated at this temperature without an inhibiting accumulation of VFAs particularly acetate. Hence, a process temperature of $45^{\circ} \mathrm{C}$ was chosen for this study, in order to contribute towards finding the optimum conditions for future $\mathrm{AD}$ systems.

Running a reactor at $45^{\circ} \mathrm{C}$ still has two major drawbacks: a prolonged initial lag phase and a comparably low $\mathrm{CH}_{4}$ concentration in the biogas compared with colder temperatures. Biochar has been reported to reduce the lag phase and increase the $\mathrm{CH}_{4}$ concentration at the same time. Moreover, it is assumed to promote clustering of microbes and to improve the process stability. Therefore, this research investigates biochar addition to lab-scale $\mathrm{AD}$ systems operated at $45^{\circ} \mathrm{C}$, which is novel and has never been done before. Moreover, a strong focus lies on microbial community characterisation. Relevant research is scarce and urgently required since a properly working microbiota is crucial for a balanced $\mathrm{AD}$ process. So far, little data are available on microbial communities at $45^{\circ} \mathrm{C}$ process temperature with cattle slurry as main substrate, and none at all concerning biochar addition.

We hypothesise that (i) biochar addition increases the methane production in an $\mathrm{AD}$ system treating agricultural waste at $45^{\circ} \mathrm{C}$, (ii) the addition of biochar facilitates the degradation of lignocellulose-rich biomass, and (iii) the addition of biochar shortens the initial lag phase typically found in $\mathrm{AD}$ at $45^{\circ} \mathrm{C}$. Moreover, we hypothesise that biochar addition does not evoke a fundamental change of the microbiota in the bioreactor and that the whole consortium still works in a balanced way.

\section{Material and Methods}

\subsection{Inoculum and Substrate}

Fresh cattle slurry, collected at a local farm (Abenthum, Innsbruck, Austria) was used as start-up substrate and for all upcoming feeding events. Immediately after collection (November 6, 2018), the slurry was sieved $(\sim 2 \mathrm{~mm})$ and stored at $4^{\circ} \mathrm{C}$ until use. Corn straw that was cut by hand into small pieces served as co-substrate. One gram of coarsely cut straw fibres was filled together with glass beads (to avoid floating) into mesh bags and the bags were then sealed with plastic clips (Laurel, Aichwald, Germany).

\subsection{Biochar Production and Characterisation}

The biochar was produced from corn stover biomass, which was obtained from MTN Bree market, Johannesburg, South Africa. The material was chopped to a particle size of $1 \mathrm{~mm}$ before pyrolysis. A tube furnace under slow pyrolysis condition of $600^{\circ} \mathrm{C}$ at a heating rate of $11^{\circ} \mathrm{C} \mathrm{min}^{-1}$ with a residence time of $1 \mathrm{~h}$ was used. Nitrogen gas flowing at $230 \mathrm{~mL} \mathrm{~min}{ }^{-1}$ was used to create anoxic conditions during heating. Proximate, ultimate and $\mathrm{pH}$ analyses were con- 
ducted in duplicate [39, 40]. The Brunauer-Emmet-Teller (BET) method for surface area, total pore volume and pore size determination by measuring of $\mathrm{N}_{2}$ adsorption using an ASAP 2460 instrument (Micromeritics, Georgia, USA) was implemented [41, 42]. The surface morphology of the biochar was determined using a VEGA 3 XMU scanning electron microscope (SEM) (Tescan, Czech Republic) equipped with an X-Max energy dispersive x-ray (EDX) analyser (Oxford Instruments, UK). For SEM, samples were mounted unto a stud using a double-sided carbon tape and analysed with an accelerating voltage of $15 \mathrm{kV}$.

\subsection{Experimental Setup}

Nine lab-scale biogas reactors [4] with a total volume of $2.35 \mathrm{~L}$ were used to assess the effect of biochar addition to an $\mathrm{AD}$ system. At the start of the experiment, the reactors were filled with 700 $\mathrm{mL}$ of sieved cattle slurry that was diluted 1:4 (v/v) with deionized water. Every three reactors were amended with 0 (reactors 1-3), 0.25 (reactors 4-6) and $0.5 \mathrm{~g}$ biochar $\mathrm{g}^{-1}$ volatile solids (VS) (reactors 7-9), the reactors were shaken, and the straw-filled mesh bags were added. After sparging the headspace with pure nitrogen gas (purity 2.5, Messer, Germany) to establish anoxic conditions, the reactors were sealed and placed in an incubator set to $45^{\circ} \mathrm{C}$. The reactors were then operated in batch mode over $22 \mathrm{~d}$. Physico-chemical and microbiological characteristics were determined regularly. After the daily gas measurements, the reactors were manually shaken for 10 $\mathrm{s}$ to avoid sedimentation and to guarantee a homogeneous reactor content. The reactors with $0 \mathrm{~g}$ of biochar addition served as controls.

Through the data collection process, it was noticed that reactor 2 (one of the control reactors) could not hold pressure, possibly due to leakages caused by an improper alignment of the sealing gasket of the reactor. Hence, reactor 2 was completely excluded from the study and the results for the control group were thus calculated from duplicates rather than from triplicates

\subsection{Biogas Yield and Composition}

The differential pressure $(\Delta P)$ between the headspace of each reactor against ambient pressure was measured daily with a digital manometer (GDH 200-13, GHM Greisinger, Germany). This differential pressure was used to calculate the biogas volume (Yield ${ }_{b}$ ) according to Eq. (1) corrected to standard conditions $\left(0^{\circ} \mathrm{C}, 1013 \mathrm{hPa}\right)$. To account for the water vapour phase and correct the biogas to dry conditions (which is beneficial when comparing gas yields with other studies), the temperature specific dry biogas factor (DBF) [43] was included:

$$
\text { Yield }_{b}[N m L]=\frac{\Delta P[h P a] * \text { headspace }[m L] * D B F(T)}{1013 h P a}
$$

Biogas quality $\left(\mathrm{CH}_{4}, \mathrm{CO}_{2}\right.$ and $\left.\mathrm{H}_{2} \mathrm{~S}\right)$ was measured daily except for the first day using an infrared-based biogas analyser (Geotech 5000, Geotechnical Instrument, UK). For each measurement, 100 $\mathrm{mL}$ of biogas was extracted from the headspace of each reactor immediately after the pressure measurement. Thereafter, the pressure in the reactor headspace was zeroed to avoid any over-pressure or vacuum in the digester at the beginning of the new measurement period. In the case of negative pressure, the headspace was flushed with pure $\mathrm{N}_{2}$ gas (purity 2.5, Messer, Germany).

\subsection{Physico-Chemical Analyses}

Dry matter (DM) content, VS and the $\mathrm{pH}$ were determined twice a week. Fresh sludge samples from each reactor were dried overnight at $105^{\circ} \mathrm{C}$ (UF110, Memmert, Germany) and the weight loss was measured. For VS, the weight loss after incinerating the dried samples in a muffle furnace (CWF 1100, Carbolite, Gero, Germany) at $550^{\circ} \mathrm{C}$ for $5 \mathrm{~h}$ was calculated. The $\mathrm{pH}$ was assessed in freshly extracted reactor sludge with a glass electrode (Primatrode 6.0228.020, Metrohm, Switzerland) connected to a portal $\mathrm{pH}$ meter (826 pH mobile, Metrohm, Switzerland). Reactor alkalinity was determined at the beginning and the end of the study with 2-point titration to $\mathrm{pH} 4.4$ and $\mathrm{pH} 5.0$ using $0.1 \mathrm{~N}$ sulphuric acid (Merck, Germany). Based on the amount of acid added, the FOS/TAC ratio was then calculated according to Bensmann et al. [44] with Eq. (2):

$$
\frac{F O S}{T A C}=\frac{\left(\left(V_{p H_{4.4}}-V_{p H_{5}}\right) * \frac{20}{V_{d i g}} * \frac{N_{H_{2}} S_{O_{4}}}{0.1} * 1.66-0.15\right) * 500 * V_{d i g}}{0.5 * N_{H_{2} S O_{4}} * V_{p H_{5}} * M_{C a C O} * 1000}
$$

To quantify the degradation of lignocellulose-rich straw fibres, the mesh bags were weighed at the beginning and the end of the experiment and the weight loss was determined. Prior to weighing the mesh bags at the end of the study, they were washed with deionized water and dried overnight at $105^{\circ} \mathrm{C}$ as described for DM. VFA and $\mathrm{NH}_{4}{ }^{+}$were quantified out of frozen $\left(-20^{\circ} \mathrm{C}\right)$ sludge samples on a weekly basis. After thawing, the samples were centrifuged for $10 \mathrm{~min}$ at 20,000 g (Eppendorf 5804R, Germany) and the supernatant was diluted with distilled water: 1:2 (v/v) for VFA and 1:10 (v/v) for $\mathrm{NH}_{4}{ }^{+}$. Samples were then sterile filtered through a cellulose filter with a pore size of $0.2 \mu \mathrm{m}$ (Chromafil Xtra, Macherey-Nagel, Germany). VFAs were analysed on a high-performance liquid chromatography (HPLC) system (Prominence, Shimadzu, Japan) equipped with a Rezex RFQ-Fast Acid column (Phenomenex, California, USA). The HPLC analysis was done as described in Hupfauf et al. [4]. Ammonium contents were determined on the same HPLC system using the flow injection method [45] and a modified OPA/NAC reagent mix as described by Meseguer-Lloret et al. [46].

\subsection{DNA Extraction and 16S Amplicon Sequencing}

Microbial community analysis was conducted at the start and the end of the experiment. DNA was extracted with a NucleoSpin Soil extraction kit (Macherey-Nagel, Germany) out of frozen $\left(-80^{\circ} \mathrm{C}\right)$ reactor sludge samples. The extraction protocol followed the instruction manual with some minor adaptations: 450-500 mg of sludge was poured into Bead Tubes and SL1 was used as lysis buffer. Sample lysis was accomplished with a FastPrep-24 device (MP Biomedicals, California, USA) at room temperature, following the suggested settings $\left(5 \mathrm{~m} \mathrm{~s}^{-1}, 30 \mathrm{~s}\right)$. DNA elution was done in two steps with each $30 \mu \mathrm{L}$ of PCR water (Rotipuran Low Organic Water, Roth, Germany). The final DNA extracts were stored at $-20^{\circ} \mathrm{C}$ in low-binding reaction tubes (Eppendorf, Germany) until use. Gel electrophoresis (12 min, $100 \mathrm{~V}$ ) on a 1\% (w/v) agarose gel with Midori Green DNA dye (Nippon Genetics, Japan) was used to appraise the DNA extraction. Finally, DNA was quantified 
with a Nanodrop 2000C spectrophotometer (Thermo Fisher Scientific, Massachusetts, USA) and the samples were sequenced by a commercial company (Microsynth, Switzerland) using next-generation sequencing (NGS).

NGS was done on an Illumina MiSeq device targeting the bacterial/archaeal V4 region of the 16S rRNA ( $2 \times 250 \mathrm{bp}$ ). The universal primers 515f (5'-GTGCCAGCMGCCGCGGTAA-3') and 806r (5'-GGACTACHVGGGTWTCTAAT-3') were used as suggested by Caporaso et al. [47] and NGS data analysis was done using the CoMA pipeline [48]. After assembling paired-end reads, primers and linker sequences were trimmed off. In the following quality filtering step, reads with an average Phred quality score $<30$ (representing a base call accuracy $>99.9 \%$ ) and/or a deviation $> \pm 5 \%$ compared with the mode sequence length were dropped from the analysis. Sequence alignment on a 97\% level and the taxonomic assignment was done with the BLAST algorithm and the SILVA SSU (release 132) database. In cases where an operational taxonomic unit (OTU) could not be assigned to SILVA SSU, Greengenes (release 13_5) served as backup database. During post-processing, rare OTUs with $<5$ occurrences over all samples were excluded and samples were randomly subsampled to a common depth of 19,048 reads after checking rarefaction curves. Both are commonly applied strategies in order to allow a proper comparison of the microbial communities in each reactor.

\subsection{Statistical Analysis}

Significance was determined at $\mathrm{p} \leq 0.05$. Descriptive statistics, analyses of variance (ANOVA), Pearson correlations and post-hoc tests (with Bonferroni correction) were calculated with Excel 2016 (Microsoft, Washington, USA) and SPSS 24 (IBM, New York, USA). Principal component analysis (PCA) and redundancy analysis (RDA) were conducted with Canoco 5 [49]. Prior analyses, data were centred, standardised (only PCA) and log-transformed $(\ln (x+1))$. Shannon-Wiener diversity (H'), Pielou's evenness (J') and Chao1 richness were calculated based on archaeal and bacterial OTUs using the following Eq. (3), (4) and (5), respectively:

$$
\begin{gathered}
H^{\prime}=-\sum_{i=1}^{R} p_{i} * \log _{2} p_{i} \\
J^{\prime}=\frac{H^{\prime}}{H^{\prime} \text { max }} \\
\text { chao } 1=R+\frac{F_{1} *\left(F_{1}-1\right)}{2 *\left(F_{2}+1\right)}
\end{gathered}
$$

where $p_{i}$ is the proportion of reads belonging to the $i^{\text {th }}$ OTU and $\mathrm{R}$ is the samples OTU count. $\mathrm{H}_{\max }^{\prime}$ is the maximum Shannon-Wiener index for a sample and can be calculated as follows: $\mathrm{H}_{\max }^{\prime}=\log _{2}$ R. $\mathrm{F}_{1}$ is the number of singletons (OTUs with only one sequence), $F_{2}$ the number of doubletons (OTUs with only two sequences). Graphics were created either with the CoMA pipeline or with in-house Matlab- and Python scripts. In the taxonomic plots (Fig. 7, Fig. 8), OTUs with an abundance $<1 \%$ were excluded.

\section{Results and Discussion}

\subsection{Substrate and Biochar Characteristics}

Cattle slurry, maize straw and biochar were initially analysed in order to characterize all applied substrates in detail (Table S1). The O/C ratio of the biochar indicates the extent of hydrophobicity of the biochar. The lower the O/C ratio, the less water can be absorbed by the biochar [50]. This is important as water absorption in an $\mathrm{AD}$ process reduces the interaction capacity of the microbial community with the substrate. Furthermore, the extent of hydrophobicity is a property of an adsorbent material indicating the capacity for $\mathrm{CO}_{2}$ adsorption [51]. A lower ratio of $\mathrm{H} / \mathrm{C}$ indicates higher stability of the biochar with highly carbonised and aromatic structures. It also signifies that possible organic content in the biochar has been devolatilised and therefore, the biochar will not necessarily degrade under anoxic conditions during the period of digestion [52]. Low $\mathrm{O} / \mathrm{C}(0.28)$ and $\mathrm{H} / \mathrm{C}(0.03)$ ratios in this study indicate the extent of aromatic condensation in the biochar [17, 50, 53]. The SEM images show the structural profile of the biomass before (a) and after (b) pyrolysis (Fig. S1). The biochar surface area $\left(0.49 \mathrm{~m}^{2} \mathrm{~g}^{-1}\right)$ is very low compared to $3.19-29 \mathrm{~m}^{2} \mathrm{~g}^{-1}$ for non-activated biochar from corn stover [54, 55]. The pore size indicates that the pyrolysis process temperature facilitated the formation of meso-pores on the biochar surface. Micro-pores and meso-pores are preferred pore sizes on biochar surface to facilitate the creation of biofilms, promote the enrichment and the clustering of similar microbial communities [23, 50, 56].

\subsection{Gas Measurement and Physico-Chemical Analysis}

The biogas yield followed the similar trend of a long acclimatisation phase that characterises $\mathrm{AD}$ at $45^{\circ} \mathrm{C}$ as previously reported [4] (Fig. 1(a)). It was noticed that despite an increasing total biogas yield the share of $\mathrm{CH}_{4}$ was low compared to $\mathrm{CO}_{2}$ during the first $17 \mathrm{~d}$ of the experiment. Biochar addition did not shorten this initial lag phase, neither at the low concentration nor at the higher one. This is contrary to what we had expected since we had assumed that the pH-balancing properties of biochar as well as its potential for creating biofilms might facilitate the microbial acclimatisation phase and reduce the duration until a steady state is reached. Obviously, the complex community structure including various syntrophic interactions, which is found at this temperature demands a certain time to establish, irrespective of the addition of a supporting agent. This however, needs to be proven also for higher biochar concentrations as well as for other substrate combinations. Particularly the latter may play a crucial role since highly specific microbial consortia are introduced to the process with the substrate. After day 17, the methane concentration started to increase rapidly, resulting in a $\mathrm{CH}_{4} / \mathrm{CO}_{2}$ ratio of 1.2 at the end of the experiment (Fig. 1(b)). As a result, the methane yield dramatically increased from day 17 onwards (Fig. 1(c)). Surprisingly, the addition of a low concentration of biochar negatively affected the biomethane yield by $10.2 \%$, whereas the high concentration of biochar increased the methane yield by $3.3 \%$ compared to the control. However, these changes were not statistically significant and we assume that in this setup biochar addition does not affect the biogas production at all. This supports the results of Shao et al. [27], who 

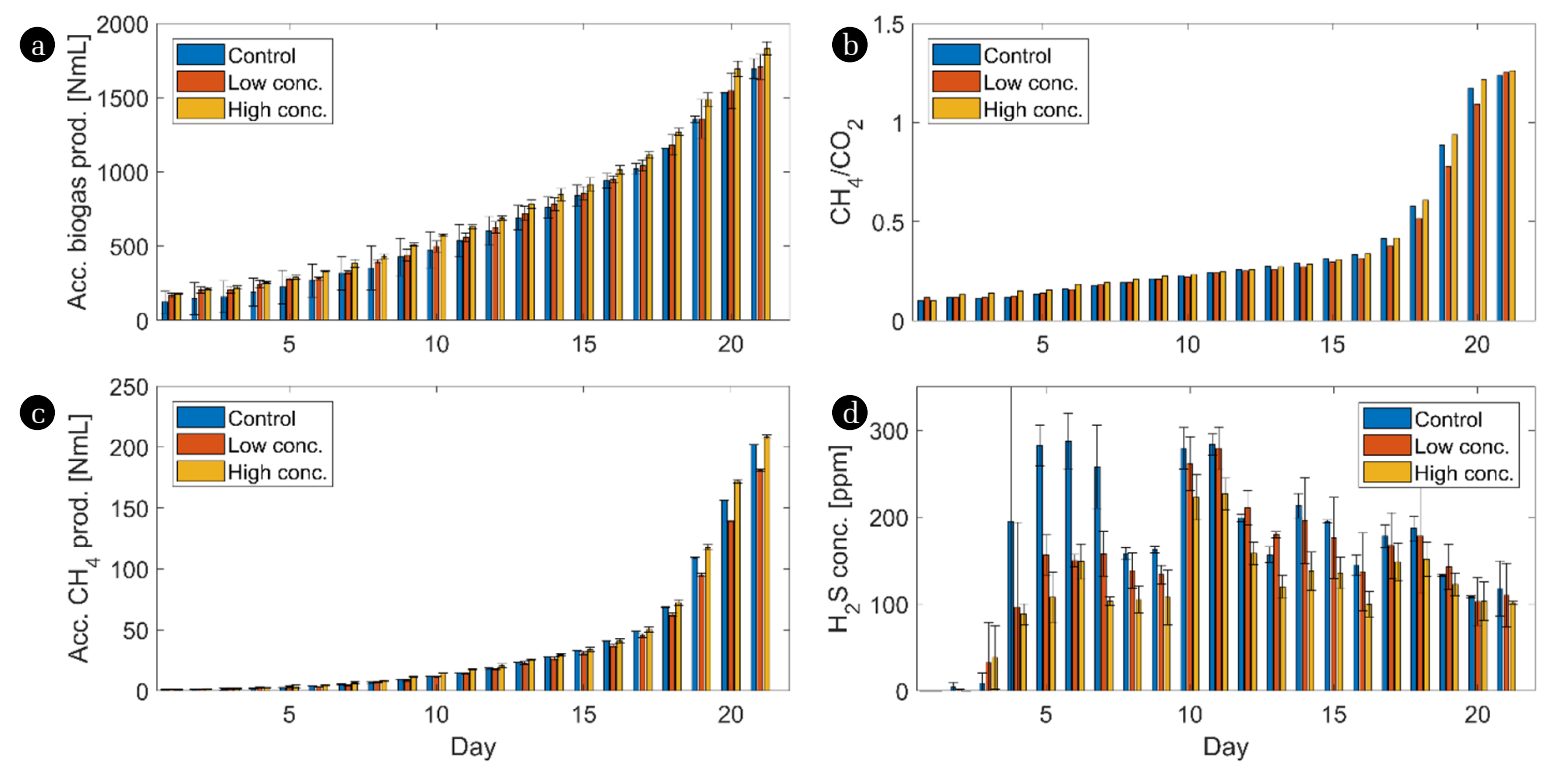

Fig. 1. Accumulated biogas production (a), $\mathrm{CH}_{4} / \mathrm{CO}_{2}$ ratio (b), accumulated methane yield (c) and hydrogen sulphide content (d) of lab-scale bioreactors operated over a period of 22 days at $45^{\circ} \mathrm{C}$. Different colours indicate the addition of low $\left(0.25 \mathrm{~g} \mathrm{~g}^{-1} \mathrm{VS}\right)$ and high $\left(0.5 \mathrm{~g} \mathrm{~g}^{-1}\right.$ VS) concentrations of biochar. Reactors without biochar addition served as control. All plots show the means \pm standard deviation $(\mathrm{n}=3$ ).

concluded that the supporting properties of biochar are only decisive for stressed or inhibited $\mathrm{AD}$ systems. In undisturbed $\mathrm{AD}$ systems as in this study, however, only minor effects are to be expected.

Aside from the $\mathrm{CH}_{4}$ concentration, the addition of biochar evoked a reduction of the $\mathrm{H}_{2} \mathrm{~S}$ concentration in the biogas by $23.3 \%$ and $37.5 \%$ for low and high concentration, respectively, compared to the control (Fig. 1(d)). The reduction of the $\mathrm{H}_{2} \mathrm{~S}$ was tested to be statistically significant $(\mathrm{p}=0.002)$. We assume that biochar functions here as an effective sorbent agent, a property that has already been reported for soil and other aqueous environments [57]. This is important since $\mathrm{H}_{2} \mathrm{~S}$ negatively affects human health and causes major problems in biogas facilities due to its corrosive properties damaging metal compounds of bioreactors, sensors, gas turbines and biogas upgraders $[58,59]$. Our data show that biochar addition might be a potential approach for managing $\mathrm{H}_{2} \mathrm{~S}$ problems in $\mathrm{AD}$. However, these findings need to be confirmed also for other substrates or substrate combinations.

Although, biochar addition lowered $\mathrm{H}_{2} \mathrm{~S}$ concentration in biogas, its effect in increasing the calorific value of the gas through increased methane concentration could not be supported because there was no significant difference in the $\mathrm{CH}_{4}$ concentration between the treated reactors and the control reactor. Notwithstanding, several research results showed that the effect of biochar to $\mathrm{AD}$ is still not yet well understood due to divergent results. Shen et al. [60] reported that as soon as the biochar concentration increased in the $\mathrm{AD}$, the accumulated biogas yield decreased and the methane concentration increased at the same time. Taking both factors together, the biomethane yield was similar to that of the control and no clear effect was found for the addition of biochar. Shao et al. [27] concluded that the addition of biochar to an already well-buffered system is insignificant but may show a positive effect for stressed $\mathrm{AD}$ systems. This is also supported by the results of Giwa et al. [61]. At low organic loading rates (1.02-1.62 $\mathrm{g} \mathrm{VS} \mathrm{L}^{-1} \mathrm{~d}^{-1}$ ), the performance of the control and the reactors with biochar were similar but as organic loading rate was increased beyond $1.62 \mathrm{~g}$ VS L ${ }^{-1} \mathrm{~d}^{-1}$, the control digester gradually acidified while the biochar-amended digester continued with stable biogas production. Taking all this together, we assume a general balancing effect of biochar at $45^{\circ} \mathrm{C}$ when added to $\mathrm{AD}$ systems disturbed by various reasons, including the accumulation of $\mathrm{H}_{2} \mathrm{~S}, \mathrm{NH}_{4}{ }^{+}$, or VFAs. For $\mathrm{NH}_{4}{ }^{+}$- and VFA accumulation, however, this still needs to be verified.

Among other parameters, the stability of an $\mathrm{AD}$ process can be verified by testing the $\mathrm{pH}$, ammonium, DM, VS, and VFA levels in the reactor sludge. The $\mathrm{pH}$ in all samples decreased as the digestion process proceeded until day 17 (Fig. 2(a)); thereafter, the $\mathrm{pH}$ started to increase. This can be explained with an ongoing accumulation of VFAs until this time point. Even though the $\mathrm{pH}$ in the biochar-amended reactors was slightly higher, the trend was not significant. We assume that biochar may indeed be used as a pH-balancing agent for $\mathrm{AD}$ reactors as suggested by other authors [2, 18]; however, higher biochar concentrations as applied in the present study might be required in order to gain a significant effect. Moreover, digesting other substrates than cattle slurry and corn straw might lead to divergent results and need to be tested before making general suggestions.

The ammonium concentrations in all samples were similar without any fluctuation throughout the experiment (Fig. 2(b)). Furthermore, the ammonium concentration lay within the expected range for cow manure (ca. $2 \mathrm{~g} \mathrm{~L}^{-1}$ ) when considering the dilution in the presented experiment. Contrary to our assumption, biochar addition did not affect the ammonium concentration in any way ( $p=0.588$ ). This contradicts previous reports according to which biochar is highly effective when it comes to the removal of inhibitors, particularly ammonium, from biogas reactors [62-64]. Ammonium levels did not exceed an inhibitory concentration [65] in this study 

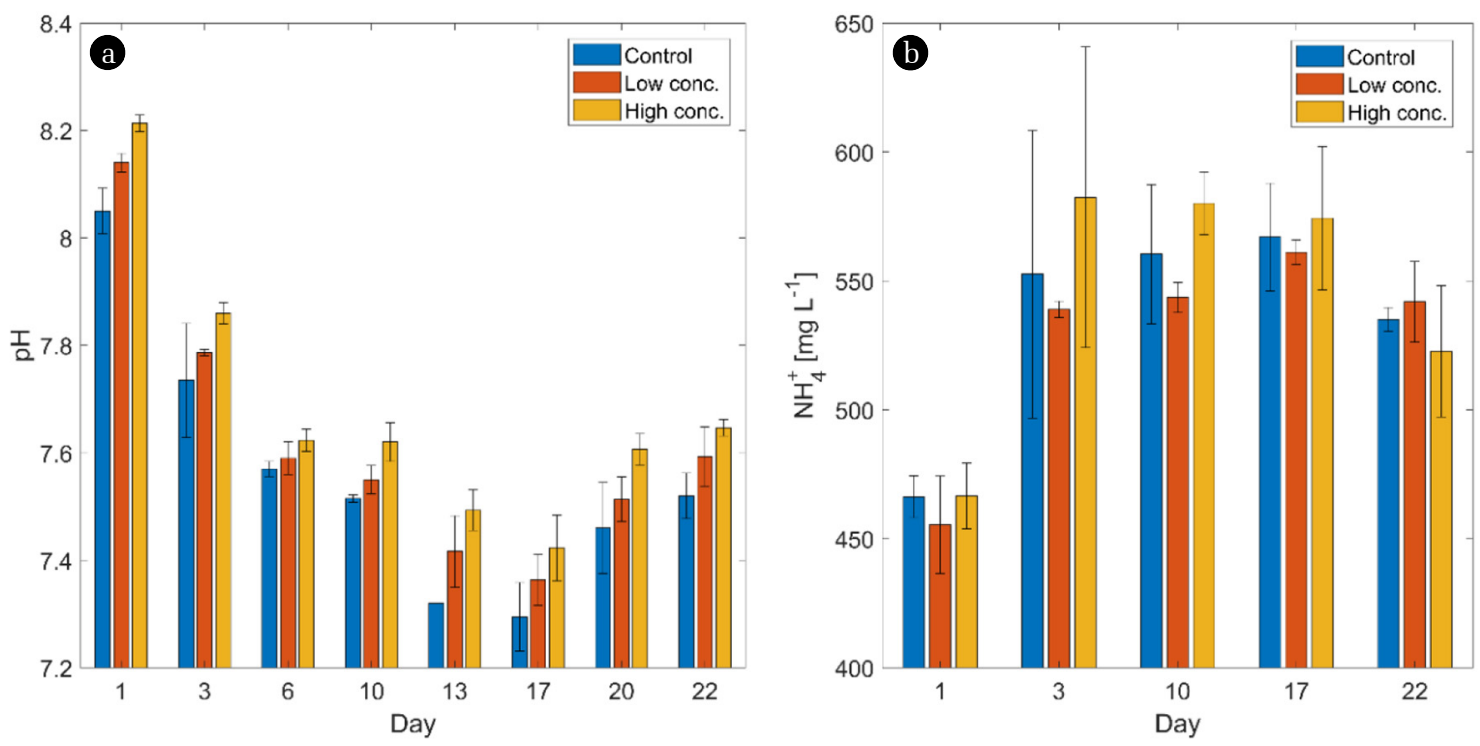

Fig. 2. The $\mathrm{pH}$ (a) and ammonium levels (b) in lab-scale bioreactors operated at $45^{\circ} \mathrm{C}$ over a period of 22 days. Different colours indicate the addition of low $\left(0.25 \mathrm{~g} \mathrm{~g}^{-1} \mathrm{VS}\right)$ and high $\left(0.5 \mathrm{~g} \mathrm{~g}^{-1} \mathrm{VS}\right)$ concentrations of biochar. Reactors without biochar addition served as control. The plot shows the means \pm standard deviation $(n=3)$.

and were hence not causing any process disturbances. However, further studies investigating $\mathrm{AD}$ systems suffering from high ammonium loads are needed. In this respect, also the substrate compositions needs to be considered as discussed for $\mathrm{pH}$ effects.

The DM content was significantly affected by the addition of biochar ( $p=0.005)$, but not by the factor "time" $(p=0.406)$. Except for day 20, reactors amended with the high biochar concentration showed the highest DM content (Fig. S2(a)). However, no accumulation over time was observed for any of the investigated bioreactors, pointing towards a stably running system without overload or starvation. Contrary to DM, VS was neither affected by biochar addition $(p=0.053)$ nor by the factor "time" $(p=0.149)$ (Fig. S2(b)).

Looking at VFAs shows that throughout the entire experiment, no butyrate was detected in any of the reactors (data not shown). The same was reported by Hupfauf [4] in a long-term experiment over 6-months at $45^{\circ} \mathrm{C}$. In another long-term experiment, butyric acid was not detected at $35^{\circ} \mathrm{C}$ and only at a concentration of 8 $\mathrm{mg} \mathrm{L} \mathrm{L}^{-1}$ at $45^{\circ} \mathrm{C}$ [37]. However, as temperature increased to $55^{\circ} \mathrm{C}$, butyric acid levels increased to $131 \mathrm{mg} \mathrm{L}^{-1}$. It could not be ascertained if biochar facilitated the rapid reduction of butyric acid, however, it can be concluded that over a long term, digesting at $45^{\circ} \mathrm{C}$ may eliminate butyric acid in the $\mathrm{AD}$ process. The acetate concentration gradually increased over time until day 17 after which it suddenly decreased below detection limit (Fig. 3(a)). The peak of acetate was recorded on day 17 corresponding to the sharp rise in the biogas production process. This is a strong indication that the $\mathrm{AD}$ process was first imbalanced until day 17 , leading to a continuous accumulation of VFAs, particularly acetate. As soon as the microbiota fully adapted to the process conditions, the system recovered and all of the acetate was turned over into methane. Such an extensive initial lag phase was already reported before by others [4, 37], pointing towards a general characteristic of $\mathrm{AD}$ at $45^{\circ} \mathrm{C}$.
It was observed that biochar addition had no influence on the acetate concentration in the samples ( $p=0.987$ ).

Propionate was not detected during the first week of the experiment, but it was found from day 10 onwards and reached a peak on day 17, again corresponding to the sudden rise in biomethane production (Fig. 3(b)). At the end of the experiment, a decline was noticed in the propionate concentration especially for the samples with high biochar concentration. The explanation for that might be the same as for acetate: as soon as a balanced and proper-working $\mathrm{AD}$ system has been established, accumulated VFAs were utilized and methane was produced out of it (either directly through acetoclastic $\mathrm{AD}$ or indirectly through syntrophic acetate oxidation and hydrogenotrophic $\mathrm{AD}$ ). The addition of biochar did not show any significant effect on the propionate concentration in the reactors at $\mathrm{p}<0.05(\mathrm{p}=0.621)$.

The FOS/TAC gives information about the ratio of VFAs and the buffering capacity of the digester. Therefore, it is an important parameter for controlling the stability of a biogas reactor and indicates process disturbances caused for instance by organic overloading. All reactors showed considerably higher values at the beginning of the experiment than at the end (Fig. S3). The control had a 59.7\% reduction, whereas the low and high biochar amended digesters showed a $64.3 \%$ and $65.8 \%$ reduction, respectively, compared to day 1 . Biochar addition, however, did not show any significant effect $(p=0.709)$. This was unexpected since biochar is usually known to increase the buffering capacity of $\mathrm{AD}$ systems [2]. The insignificance of the buffer capacity of biochar in this study may be attributed to the already well-buffered $\mathrm{AD}$ system facilitated by the type of substrate used (cattle slurry). We assume that the amount of added biochar was not high enough to induce a measurable effect.

In order to quantify the degradation of lignocellulose-rich biomass, the weight loss of straw fibres was determined inside mesh 

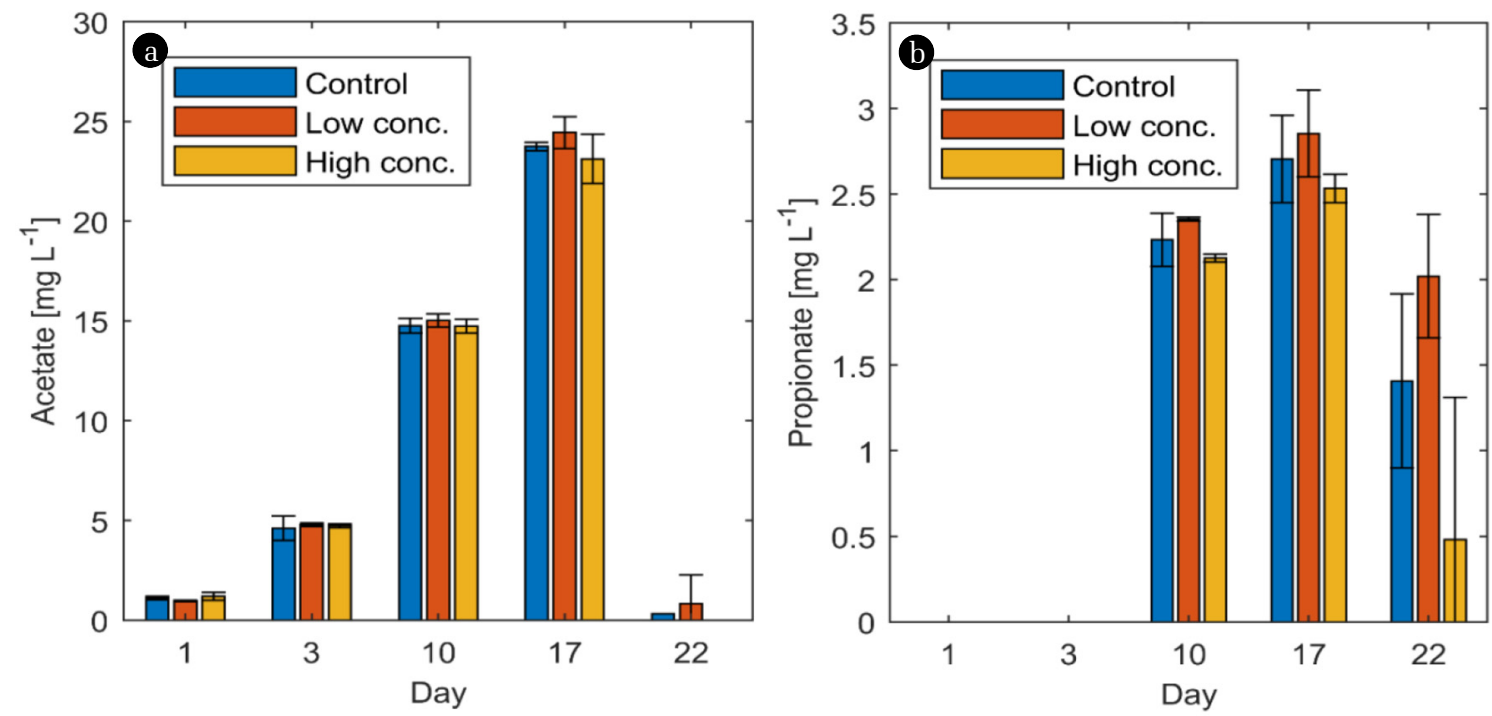

Fig. 3. Acetate (a) and propionate levels (b) in lab-scale bioreactors operated at $45^{\circ} \mathrm{C}$ over a period of 22 days. Different colours indicate the addition of low (0.25 $\left.\mathrm{g} \mathrm{g}^{-1} \mathrm{VS}\right)$ and high ( $\left.0.5 \mathrm{~g} \mathrm{~g}^{-1} \mathrm{VS}\right)$ concentrations of biochar. Reactors without biochar addition served as control. The plot shows the means \pm standard deviation $(n=3)$.

bags. After $22 \mathrm{~d}, 60.2 \%, 61.8 \%$ and $58.5 \%$ of the straw biomass were degraded within the control reactors, the reactors with a low biochar concentration and the reactors with a high biochar concentration, respectively. At least in the short term, no significant differences between the treatments were detected $(p=0.637)$. This is surprising and contradicts previous reports of an accelerated degradation of fibrous biomass [66], even though the authors suggested an optimum biochar concentration of $15 \mathrm{~g} \mathrm{~L}^{-1}$, which is approximately six times and three times higher than seen for the low and the high concentration in this study, respectively. This may at least partially explain the divergence of both studies; however, more research is needed to investigate the degradation of lignocellulose-rich biomass at $45^{\circ} \mathrm{C}$, since it represents one of the major drawbacks of $\mathrm{AD}$ when treating agricultural residues.

\subsection{Microbiological Analysis}

NGS data showed that biochar addition did not affect the OTU richness (number of different OTUs found in each reactor; $\mathrm{p}=$ 0.44) (Fig. 4(a)). The same was found for the Shannon-Wiener diversity ( $p=0.516$; Fig. 4(b)), the Chao1 richness $(p=0.78$; Fig. 4(c)) as well as for Pielou's evenness ( $p=0.556$; Fig. 4(d)). However, all parameters were influenced by the factor of time (OTU count: $p=0.001$, Shannon-Wiener diversity: $p=0.001$, Chao1 richness: $p=0.001$, Pielou's evenness: $p=0.001$ ) indicating an adaptation of the microbiota from the start of the experiment to the end, which had been expected after analysing the physico-chemical parameters. All diversity measures were significantly lower after $22 \mathrm{~d}$ of operation, pointing towards an ongoing specialisation of the microbiota towards a community that is perfectly optimized to thrive (and produce biogas) at the prevailing process conditions.

To compare the microbial communities in all reactors with each other, a PCA was conducted (Fig. 5(a)). Samples from day 1 are located on the right side, those from day 22 on the left side of the scatter plot. This means that the factor "time" had a huge impact on the microbial composition, particularly since PCA axis 1 explained a high proportion of the total variation (44\%). Samples from the start of the experiment (day 1) were distributed along the y-axis, whereas the reactors with biochar addition were closer related to each other than to the control reactors. This trend, however, is minor, since PCA axis 2 only explains $6 \%$ of the total variation. On the other hand, samples from the end of the experiment (day 22) were clearly clustered and no deviation was detected. This clearly strengthens the assumption of an ongoing specialisation of the microbiota to the process conditions, being the same for all investigated bioreactors, irrespective of biochar addition. To prove this also statistically, an RDA with forward selection was applied. The factor "time" explained $74.1 \%$ of the distribution, whereas the biochar addition only did $2.6 \%$.

The same conclusions can be drawn when looking at the PCA computed solely from archaeal data (Fig. 5(b)). Again, the factor "time" evoked the majority of the variation, whereas the addition of biochar had little to no impact. When going into detail, it turned out that Methanobrevibacter and an unknown Woesearchaeia genus were most important for characterizing the microbial community of day 1. At the end of the experiment (day 22), however, Methanosarcina and Methanoculleus were found to be the characteristic methanogens. Despite the trend being very weak, Methanosphaera, as well as Candidatus Methanoplasma, were indicators for the samples amended with biochar.

To compare the similarity/dissimilarity of the samples for each taxonomic level, Venn plots were constructed. Between day 1 and day 22, reactors shared a large proportion of phyla (31 out of 36, $86 \%$ ), classes (50 out of $62,81 \%$ ), orders (100 out of $120,83 \%$ ), families (161 out of 208, 77\%) and genera (256 out of 344, 74\%) (Fig. 6(a)). The other taxa were found either exclusively at day 1 or exclusively at day 22 , whereas none of them predominated. This shows that there was a relatively large core microbiota during 

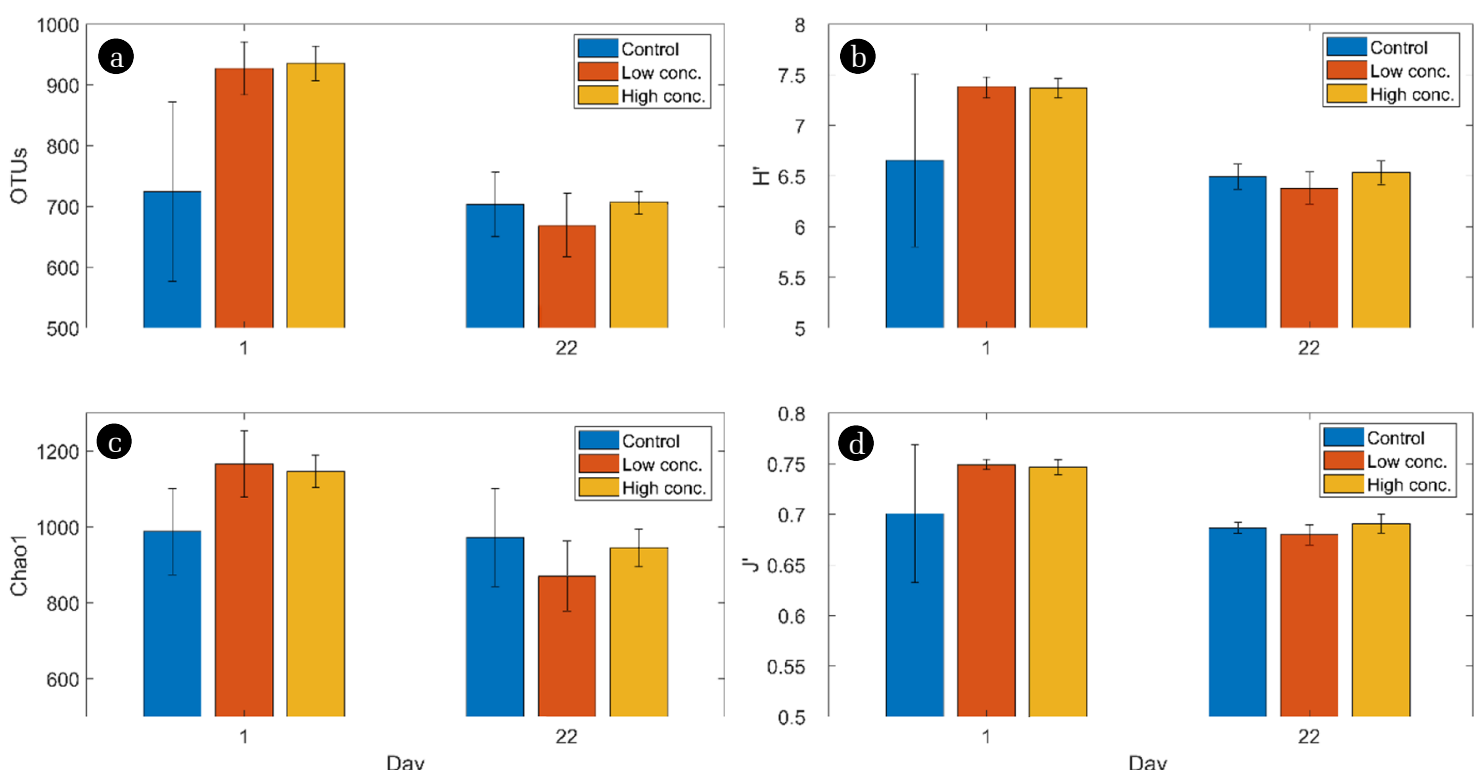

Fig. 4. OTU richness (a), Shannon-Wiener diversity $\mathrm{H}^{\prime}$ (b), Chao1 richness (c) and Pielou's evenness J' (d) calculated from $16 \mathrm{~S}$ sequencing data. Different colours indicate the addition of low $\left(0.25 \mathrm{~g} \mathrm{~g}^{-1} \mathrm{VS}\right)$ and high $\left(0.5 \mathrm{~g} \mathrm{~g}^{-1} \mathrm{VS}\right)$ concentrations of biochar. Reactors without biochar addition served as control. The plot shows the means \pm standard deviation $(n=3)$.
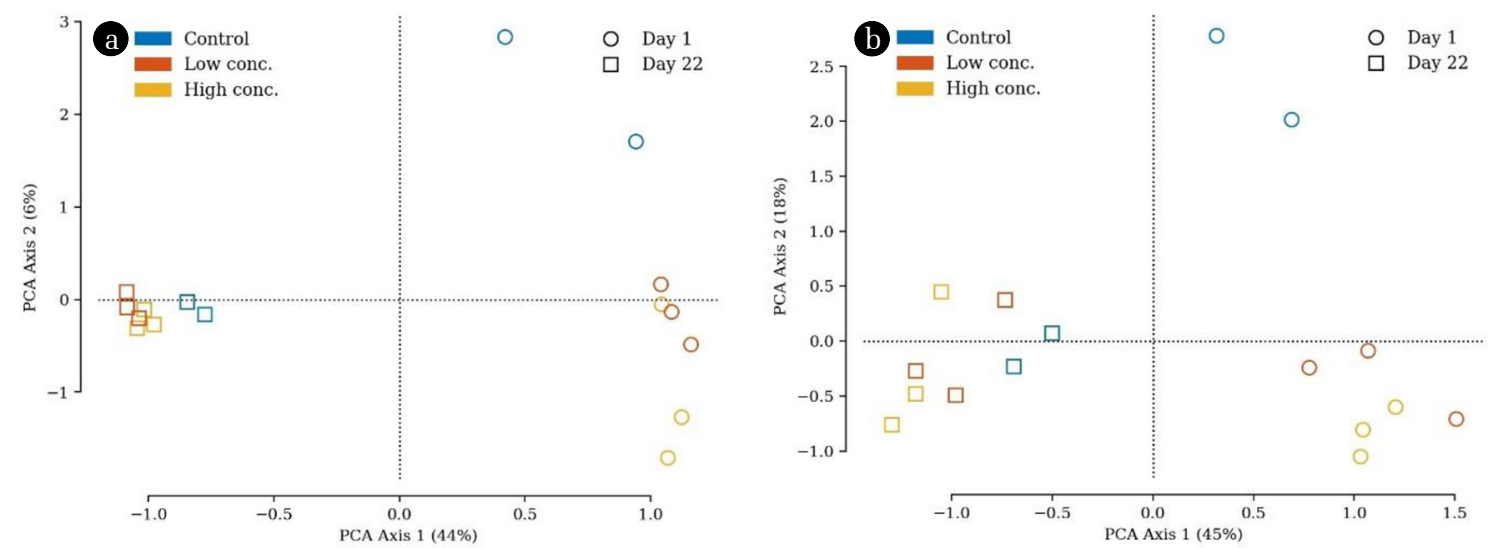

Fig. 5. Principal component analysis (PCA) calculated based on bacterial and archaeal (a) as well as solely on archaeal (b) $16 \mathrm{~S}$ sequences. Different colours indicate the addition of low $\left(0.25 \mathrm{~g} \mathrm{~g}^{-1} \mathrm{VS}\right)$ and high $\left(0.5 \mathrm{~g} \mathrm{~g}^{-1} \mathrm{VS}\right)$ concentrations of biochar. Reactors without biochar addition served as control. Different markers indicate the time point.

the whole duration of the experiment, at least when looking solely on the presence/absence of taxa. When comparing the two time points based on abundances, however, microbial communities were clearly distinguishable as shown with PCA. Taking this together led to the assumption that the distinction between both groups was mainly based on a small number of organisms that occurred at high abundances whereas the majority of bacteria/archaea was only detected at a small abundance, not decisive for distinguishing between the groups.

When comparing the different treatments (Control, Low conc., High conc.) at day 22, Venn plots again revealed a huge proportion of shared taxa for each taxonomic level (phylum: 28 out of 33, $85 \%$; class: 43 out of $54,80 \%$; order: 86 out of $109,79 \%$; family: 136 out of 184, 74\%; genus: 193 out of 298, 65\%) (Fig. 6(b)). As discussed above, this points towards a large core community when considering the overall presence/absence of taxa. In this case, however, the proportion of shared genera was considerably lower as when comparing the two time points. This is particularly interesting since the PCA and RDA results clearly indicated that the factor "time" was much more important for shaping the microbial community structure than the addition of biochar. We explain this again with the presence of a few, highly abundant organisms (a member of the core microbiota) that are dominating the microbial community irrespective of the addition of biochar. Apart from the shared taxa, the Venn plots showed that the reactors amended with a high concentration of biochar included slightly more unique taxa than the controls and the reactors amended with a low biochar concentration (e.g. at genus level: control: 15; Low conc.: 11; High 


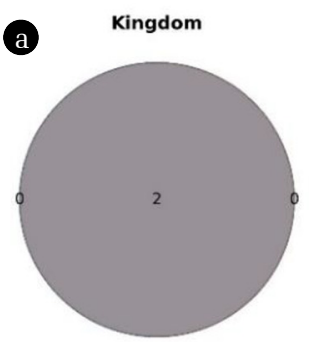

Order
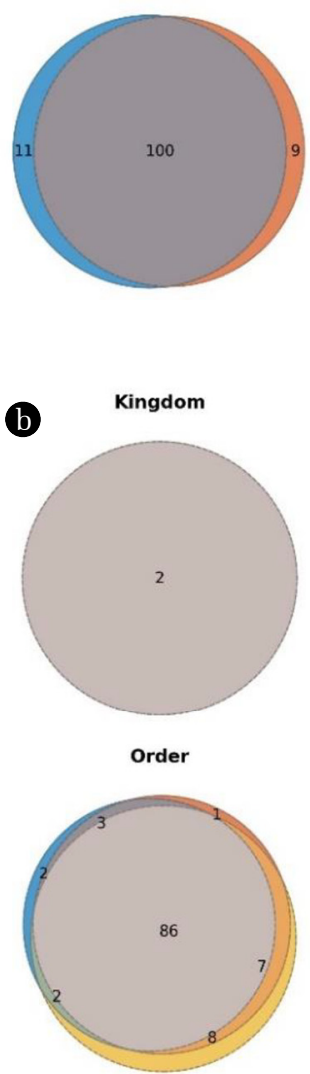

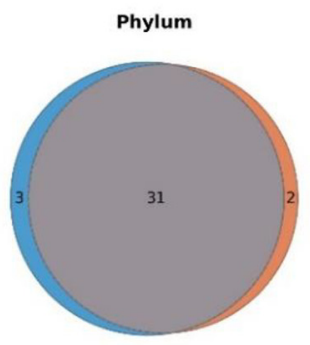

Family
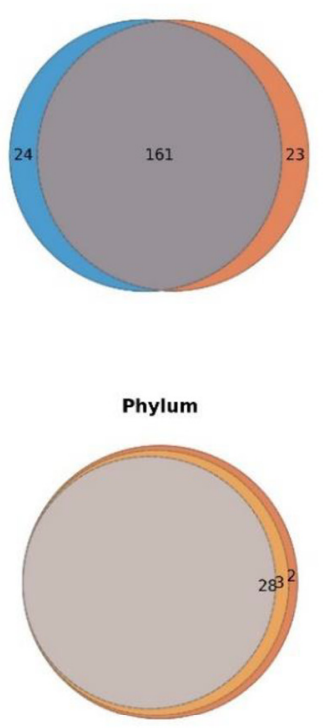

Family

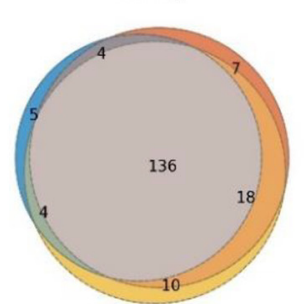

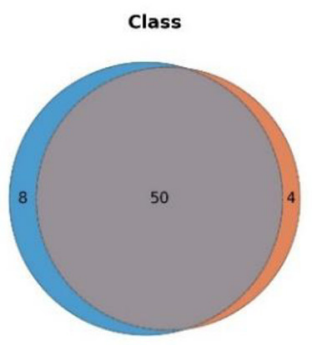

Genus
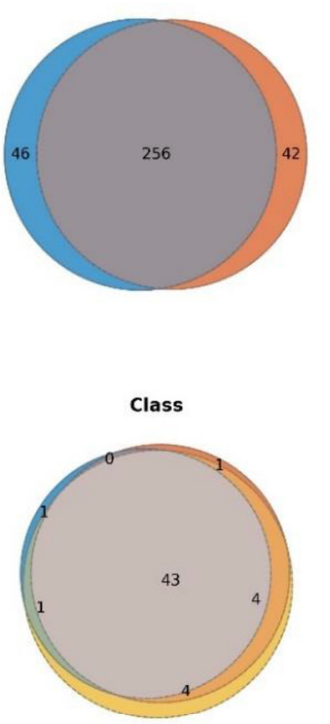

Genus

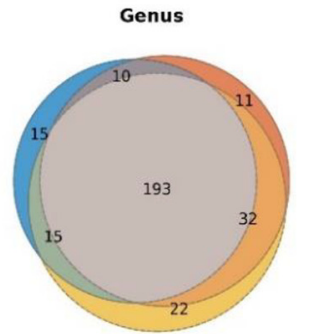

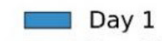

Day 22
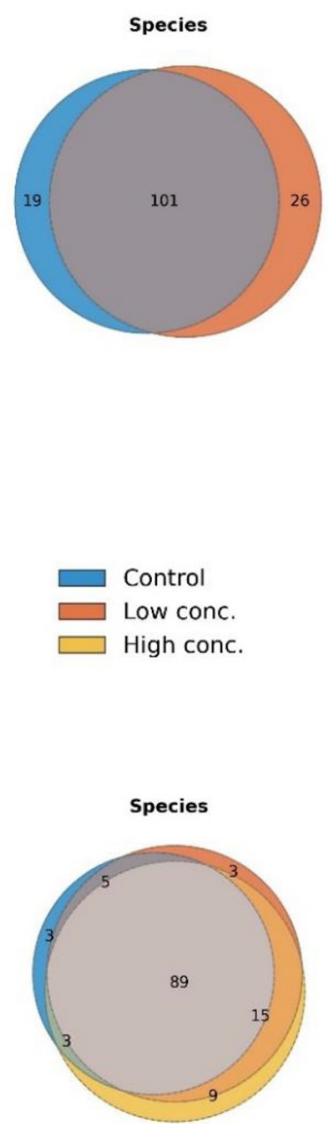

Fig. 6. Venn plots for comparing the microbiota at the beginning and end of the experiment (a) as well as to reveal the effect of biochar addition after 22 days of operation (b).

conc.: 22). This trend, however, was minor and may not be generally valid for other similar experimental setups.

A deeper analysis of the bacterial community in the reactors on family level revealed that at the beginning of the experiment, Ruminococcaceae, Rikenellaceae, Dysgonomonadaceae and "Family XI" (order Clostridiales) dominated (Fig. 7). All four groups together included $46 \%$ of all detected reads (Control: 49\%, Low conc.: 44\%, High conc.: 44\%), clearly corroborating the above assumption of a microbiota heavily dominated by only a small group of organisms. This is common for $\mathrm{AD}$ systems treating cattle slurry and was already reported before [38]. Irrespective of biochar addition, Ruminococcaceae were the most abundant family at the start of the experiment (as well as at the end; $16 \%$ of all reads). This is in line with various other studies describing the family as members of the $\mathrm{AD}$ core microbiome, particularly with animal wastes as main substrate [67-69]. Ruminococcaceae are important hydrolytic bacteria mainly degrading cellulose and hemicellulose to acetate and other VFAs [70]. Rikenellaceae is another important family frequently found in $\mathrm{AD}$ systems [67, 71]. It typically occurs in the gastrointestinal tract of animals and humans and thrives anaerobically. Glucose and other carbohydrates can be converted fermentatively to VFAs, alcohols, $\mathrm{H}_{2}$ and $\mathrm{CO}_{2}$ [72], and Nakasaki et al. [73] reported that members of this family might also be involved in the degradation of glycerol. In this study, Rikenellaceae were almost exclusively found at the beginning of the experiment, while their abundance dramatically decreased until day 22. Dysgonomonadaceae are other common members of $\mathrm{AD}$ systems [71], thriving preferably between $35^{\circ} \mathrm{C}$ and $45^{\circ} \mathrm{C}$. They utilize carbohydrates and peptides and ferment it to mainly acetate and propionate [74]. The pseudo clade "Family XI" includes various genera, for which a precise 


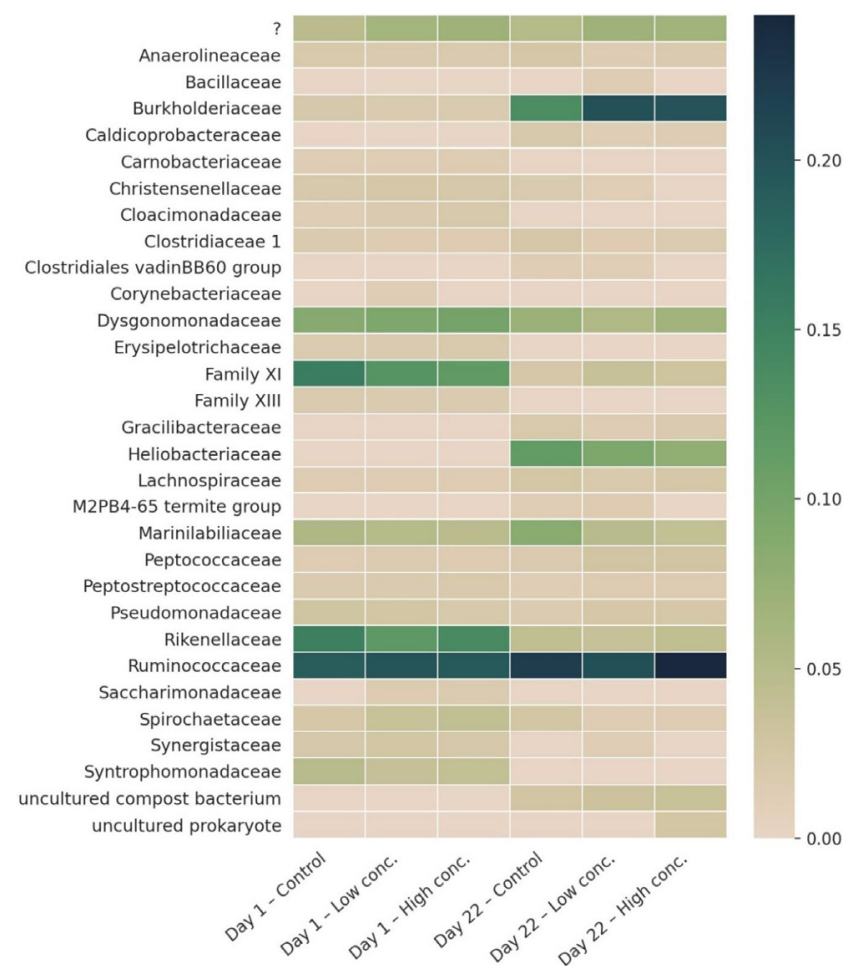

Fig. 7. Heatmap depicting the bacterial community composition of lab-scale bioreactors on family level based on 16S rRNA amplicon sequencing data. The plot shows mean values $(n=3)$ for two different time points and different amounts of biochar addition. Control: $0 \mathrm{~g} \mathrm{~g}^{-1}$ VS. Low conc.: $0.25 \mathrm{~g} \mathrm{~g}^{-1}$ VS. High conc.: $0.5 \mathrm{~g} \mathrm{~g}^{-1} \mathrm{VS}$.

taxonomic assignment was not possible. At the start of the experiment, mainly the two genera Tissierella and Sedimentibacter were detected. Tissierella are obligatory anaerobic and grow optimally at $37^{\circ} \mathrm{C}$. Moreover, they are non-fermentative, and degrade glucose and/or proteins down to acetate, propionate, butyrate, ammonia and $\mathrm{CO}_{2}[75,76]$. Sedimentibacter, on the other hand, are involved in the acetogenesis step, where VFAs are degraded to acetate and $\mathrm{H}_{2}$ [77, 78]. Wang et al. [79] reported that the organisms are vulnerable to high ammonia loads. This may explain their occurrence in this study, where the main substrate cattle slurry was diluted and hence ammonium loads were reduced, whereas in previous studies using the same (but undiluted) substrate and reactor setup, Sedimentibacter was absent $[4,38]$. After 22 d, "Family XI" members were only detected at very low numbers anymore. We assume that this might be explained at least partially with the increasing ammonium levels over the duration of the experiment.

At the end of the experiment (day 22), Ruminococcaceae still dominated the microbial communities, irrespective of the addition of biochar (18-21\% of all reads). The second most abundant family, however, was Burkholderiaceae, which was detected only at very low counts at day 0 (1-2\%). At day 22, $12 \%$ of all reads were assigned to this family within the control reactors, whereas even higher abundances were found when biochar was added (Low conc.: $18 \%$, High conc.: 17\%). Burkholderiaceae is a very diverse family in terms of both, ecological and physiological characteristics.
The most abundant genus in our reactors was Comamonas, which was also detected by other studies in $\mathrm{AD}$ reactor sludge [80-82]. Generally, this group is known for being involved in denitrification processes [83]; in $\mathrm{AD}$ systems, however, Comamonas are particularly important for the degradation of a broad range of organic acids during acidogenesis and acetogenesis [77, 84]. Apart from Comamonas, Parapusillimonas and Verticia were the most important genera among the Burkholderiaceae family, although at considerably lower abundances. However, so far, only little information is available on their precise role in $\mathrm{AD}$; even their broad occurrence in other bioreactors or $\mathrm{AD}$ systems is not well documented yet. Heliobacteriaceae is another frequently detected family at day 22, which was not found at all at the beginning of the experiment. So far, only little is known about their role in artificial biogas reactors; however, recent studies found them in rice field soil [85], paddy soil, and flooded desert soil [86]. Peng et al. [86] proved with their metatranscriptomic-based study that Heliobacteriaceae are involved in syntrophic acetate oxidation (syntrophic acetate oxidation bacteria, SAOB), where methane is produced from acetate in association with hydrogenotrophic methanogens. In addition, Noll et al. [87] speculated that Heliobacteriaceae might be involved in the degradation of propionate in rice soils when the temperature is high. This is reflected in our data, where the appearance of Heliobacteriaceae at the end of the experiment came along with a considerable decrease of both, acetate and propionate in the reactor sludge.

Looking at Archaea showed that over the whole experiment the vast majority of all reads was assigned to Methanosarcina (Fig. 8). Even though the counts were still very high, there was a decrease from the start of the experiment (Control: 98\%, Low conc.: 92\%, High conc.: $92 \%$ ) to the end (Control: $83 \%$, Low conc.: $75 \%$, High conc.: $84 \%$ ), whereas the addition of biochar showed no significant influence. A clear domination of Methanosarcina at $45^{\circ} \mathrm{C}$ is known from previous studies $[4,38]$, pointing towards highly preferable growth conditions for these methanogens, at least when cattle slurry and straw are used as main substrates. Physiologically, the organisms are highly versatile, producing methane from various substrates. Methanosarcina are the only methanogens capable of using both, the hydrogenotrophic as well as the acetoclastic pathway. Which pathway is active is generally determined by environmental factors such as $\mathrm{pH}$ and the ammonium content. Jiang et al. [88] reported that hydrogenotrophic methanogenesis prevails at high ammonium levels, whereas acetoclastic methanogenesis is preferably used at low concentrations. The relatively high ammonium loads in our reactors (typical for reactors fed with animal manure/slurry) together with the numerous occurrence of SAOBs suggests that most of the methane is produced via hydrogenotrophic methanogenesis by Methanosarcina in association with syntrophic Heliobacteriaceae species. The addition of biochar had no influence and did not affect the production of methane, neither in a positive nor in a negative direction. Apart from Methanosarcina, low numbers of Methanobrevibacter and Methanoculleus were detected. The first occurred more at the beginning of the experiment (3-4\%), whereas the latter appeared more towards the end (5-10\%). However, their abundances were small and we assume only a minor contribution of these genera to the total amount of produced biogas. 


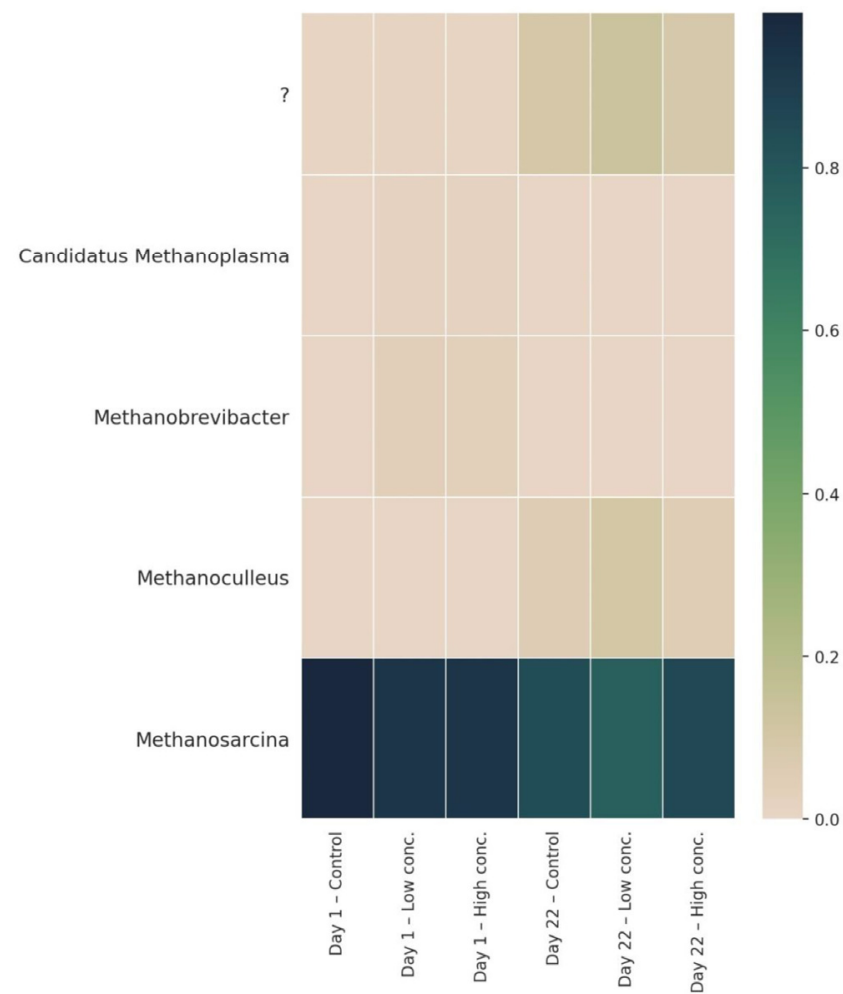

Fig. 8. Heatmap depicting the archaeal community composition of lab-scale bioreactors on genus level based on 16S rRNA amplicon sequencing data. The plot shows mean values $(n=3)$ for two different time points and different amounts of biochar addition. Control: $0 \mathrm{~g} \mathrm{~g}^{-1}$ VS. Low conc.: $0.25 \mathrm{~g} \mathrm{~g}^{-1} \mathrm{VS}$. High conc.: $0.5 \mathrm{~g} \mathrm{~g}^{-1} \mathrm{VS}$.

Summing up, the microbiota in the bioreactors underwent an adaptation process from the start to the end of the experiment. A firstly Rikenellaceae- and Dysgonomonadaceae-dominated consortium shifted towards a community, where Burkholderiaceae and Heliobacteriaceae were highly abundant. The addition of biochar did not show an effect on the microbial community composition when looking at the core microbes; however, less abundant taxa might be affected. Our results demonstrated that stable biogas production was possible, irrespective of biochar addition. We attribute this to the presence of a balanced and properly working microbiota in all reactors. Nevertheless, further studies are needed on stressed or imbalanced $\mathrm{AD}$ systems, where we expect a higher impact of biochar addition, also in terms of microbial community composition. Biochar might indeed function as a balancing agent, allowing for satisfying methane yields even under unfavourable process conditions. Moreover, studies on continuously operated bioreactors with high loading rates are needed in order to reveal the immobilizing potential of biochar for process-relevant microbes [89], particularly slow-growing organisms like methanogens [90].

\section{Conclusions}

This study monitored the start-up phase of lab-scale bioreactors fed with cattle slurry and corn straw at $45^{\circ} \mathrm{C}$, and tried to reveal the effect of biochar addition to the system. Our data showed that biochar had no influence on both, amount and composition of the produced biogas. Likewise, none of the observed stability indicators was affected, except for a reduced $\mathrm{H}_{2} \mathrm{~S}$ content at the beginning of the experiment. Further studies are needed to prove our data also for the long term in continuously running $\mathrm{AD}$ systems. Moreover, future studies should focus on disturbed systems (e.g. organic overload, $\mathrm{H}_{2} \mathrm{~S}$ problems or acidification) in order to fully reveal the potential of biochar as balancing agent in $\mathrm{AD}$ reactors operated at $45^{\circ} \mathrm{C}$. Our microbiome analysis gave vivid insight into the bacterial/archaeal dynamics during reactor start-up. As expected, the addition of biochar did not evoke considerable changes in the microbiota. Thus, for well-balanced reactor systems biochar does not offer operational advantages, if it does in unbalanced systems still needs to be investigated.

\section{Data Deposition}

All NGS data are uploaded to the European Nucleotide Archive under the accession numbers ERS3858284 to ERS3858301 within the study PRJEB34762 (https://www.ebi.ac.uk/ena/data/view/PRJEB34762).

\section{Acknowledgments}

This work was supported by the Austrian Agency for International Cooperation in Education and Research (OeAD) within the "Scientific \& Technological Cooperation" program. We thank the Abenthum family for providing cattle slurry, and Thomas Klammsteiner and Anna Winkler for their highly appreciated assistance during slurry collection and sieving.

\section{Author Contributions}

S.M. (Postdoc) created the experimental design, conducted the experiment and wrote the manuscript. O.F. (Ph.D. student) helped interpreting the NGS results and revised the manuscript.

H.I. (Professor) created the experimental design and revised the manuscript. C.M. (Professor) revised the manuscript. A.W. (Associated Professor) contributed the VFA analysis and revised the manuscript. R.M. (Ph.D. student) contributed the $\mathrm{NH}_{4}{ }^{+}$analysis and revised the manuscript. S.H. (Postdoc) created the experimental design, conducted the experiment, carried out the NGS data analyses with CoMA, performed statistical tests, wrote the manuscript and conducted the revision of the manuscript.

\section{References}

1. Schnürer A, Bohn I, Moestedt J. Protocol for start-up and operation of CSTR biogas processes. In: McGenity TJ, Timmis KN, Nogales B, eds. Hydrocarbon and Lipid Microbiology Protocols. Berlin: Springer; 2016. p. 171-200.

2. Wang D, Ai J, Shen F, et al. Improving anaerobic digestion 
of easy-acidification substrates by promoting buffering capacity using biochar derived from vermicompost. Bioresour. Technol. 2017;227:286-296.

3. Ward AJ, Hobbs PJ, Holliman PJ, Jones DL. Optimisation of the anaerobic digestion of agricultural resources. Bioresour. Technol. 2008;99:7928-7940.

4. Hupfauf S, Plattner P, Wagner AO, Kaufmann R, Insam H, Podmirseg SM. Temperature shapes the microbiota in anaerobic digestion and drives efficiency to a maximum at $45^{\circ} \mathrm{C}$. Bioresour. Technol. 2018;269:309-318.

5. Khalid A, Arshad M, Anjum M, Mahmood T, Dawson L. The anaerobic digestion of solid organic waste. Waste Manage. 2011;31:1737-1744.

6. Pavi S, Kramer LE, Gomes LP, Miranda LAS. Biogas production from co-digestion of organic fraction of municipal solid waste and fruit and vegetable waste. Bioresour. Technol. 2017;228: 362-367.

7. Appels L, Lauwers J, Degrève J, et al. Anaerobic digestion in global bio-energy production: Potential and research challenges. Renew. Sust. Energ. Rev. 2011;15:4295-4301.

8. Yang Y, Zhang Y, Li Z, Zhao Z, Quan X, Zhao Z. Adding granular activated carbon into anaerobic sludge digestion to promote methane production and sludge decomposition. J. Clean. Prod. 2017;149:1101-1108.

9. Amha YM, Anwar MZ, Brower A, et al. Inhibition of anaerobic digestion processes: Applications of molecular tools. Bioresour. Technol. 2018;247:999-1014.

10. Masebinu SO, Akinlabi ET, Muzenda E, Aboyade AO. A review of biochar properties and their roles in mitigating challenges with anaerobic digestion. Renew. Sust. Energ. Rev. 2019;103: 291-307.

11. Budzianowski WM, Wylock CE, Marciniak P. Power requirements of biogas upgrading by water scrubbing and biomethane compression: Comparative analysis of various plant configurations. Energ. Convers. Manag. 2016;18.

12. Ganesh R, Torrijos M, Sousbie P, Steyer JP, Lugardon A, Delgenes JP. Anaerobic co-digestion of solid waste: Effect of increasing organic loading rates and characterization of the solubilised organic matter. Bioresour. Technol. 2013;130:559-569.

13. García-Gen S, Rodríguez J, Lema JM. Optimisation of substrate blends in anaerobic co-digestion using adaptive linear programming. Bioresour. Technol. 2014;173:159-167.

14. Lin J, Zuo J, Gan L, et al. Effects of mixture ratio on anaerobic co-digestion with fruit and vegetable waste and food waste of China. J. Environ. Sci. 2011;23:1403-1408.

15. Shen F, Yuan H, Pang Y, et al. Performances of anaerobic co-digestion of fruit \& vegetable waste (FVW) and food waste (FW): Single-phase vs. two-phase. Bioresour. Technol. 2013;144:80-85.

16. Gao S, Huang Y, Yang L, et al. Evaluation the anaerobic digestion performance of solid residual kitchen waste by $\mathrm{NaHCO} 3$ buffering. Energ. Convers. Manag. 2015;93:166-174.

17. Sahota S, Vijay VK, Subbarao PMV, et al. Characterization of leaf waste based biochar for cost effective hydrogen sulphide removal from biogas. Bioresour. Technol. 2018;250:635-641.

18. Linville JL, Shen Y, Ignacio-de Leon PA, Schoene RP, Urgun-Demirtas M. In-situ biogas upgrading during anaerobic digestion of food waste amended with walnut shell biochar at bench scale. Waste Manag. Res. 2017;35:669-679.

19. Inyang M, Gao B, Pullammanappallil P, Ding W, Zimmerman AR. Biochar from anaerobically digested sugarcane bagasse. Bioresour. Technol. 2010;101:8868-8872.

20. Zhang J, Mao F, Loh K-C, Gin KY-H, Dai Y, Tong YW. Evaluating the effects of activated carbon on methane generation and the fate of antibiotic resistant genes and class I integrons during anaerobic digestion of solid organic wastes. Bioresour. Technol. 2018;249:729-736.

21. Kim MH, Jeong IT, Park SB, Kim JW. Analysis of environmental impact of activated carbon production from wood waste. Environ. Eng. Res. 2019;24:117-126.

22. Fagbohungbe MO, Herbert BMJ, Hurst L, et al. The challenges of anaerobic digestion and the role of biochar in optimizing anaerobic digestion. Waste Manage. 2017;61:236-249.

23. Cooney MJ, Lewis K, Harris K, Zhang Q, Yan T. Start up performance of biochar packed bed anaerobic digesters. J. Water Process Eng. 2016;9:e7-e13.

24. Chen Y, Cheng JJ, Creamer KS. Inhibition of anaerobic digestion process: A review. Bioresour. Technol. 2008;99:4044-4064.

25. Sunyoto NMS, Zhu M, Zhang Z, Zhang D. Effect of biochar addition on hydrogen and methane production in two-phase anaerobic digestion of aqueous carbohydrates food waste. Bioresour. Technol. 2016;219:29-36.

26. Mumme J, Srocke F, Heeg K, Werner M. Use of biochars in anaerobic digestion. Bioresour. Technol. 2014;164:189-197.

27. Shao L, Li S, Cai J, He P, Lü F. Ability of biochar to facilitate anaerobic digestion is restricted to stressed surroundings. J. Clean. Prod. 2019;238:117959.

28. De la Rubia MA, Riau V, Raposo F, Borja R. Thermophilic anaerobic digestion of sewage sludge: focus on the influence of the start-up. A review. Crit. Rev. Biotechnol. 2013;33:448-460.

29. Suryawanshi PC, Chaudhari AB, Kothari RM. Thermophilic anaerobic digestion: the best option for waste treatment. Crit. Rev. Biotechnol. 2010;30:31-40.

30. Sanna A, Uibu M, Caramanna G, Kuusik R, Maroto-Valer MM. A review of mineral carbonation technologies to sequester $\mathrm{CO} 2$. Chem. Soc. Rev. 2014;43:8049-8080.

31. Vlyssides AG and Karlis PK. Thermal-alkaline solubilization of waste activated sludge as a pre-treatment stage for anaerobic digestion. Bioresour. Technol. 2004;91:201-206.

32. Tan X, Liu Y, Zeng G, et al. Application of biochar for the removal of pollutants from aqueous solutions. Chemosphere 2015;125:70-85.

33. Linville JL, Shen Y, Wu MM, Urgun-Demirtas M. Current State of Anaerobic Digestion of Organic Wastes in North America. Cur. Sust. Renew. Energ. Rep. 2015;2:136-144.

34. Levén L. Anaerobic digestion at mesophilic and thermophilic temperature. $\mathrm{PhD}$ Thesis. Swedish University of Agricultural Sciences, Department of Microbiology. Uppsala. 2006.

35. Mao C, Feng Y, Wang X, Ren G. Review on research achievements of biogas from anaerobic digestion. Renew. Sustain. Energy Rev. 2015;45:540-555.

36. Vindis P, Mursec B, Janzekovic M, Cus F. The impact of mesophilic and thermophilic anaerobic digestion on biogas production. J. Achiev. Mater. Manuf. Eng. 2009;36:192-198.

37. Tian G, Yang B, Dong M, et al. The effect of temperature on 
the microbial communities of peak biogas production in batch biogas reactors. Renew. Energ. 2018;123:15-25.

38. Hupfauf S, Winkler A, Wagner AO, Podmirseg SM, Insam H. Biomethanation at $45^{\circ} \mathrm{C}$ offers high process efficiency and supports hygienisation. Bioresour. Technol. 2020;300:122671.

39. ASTM. Standard method for chemical analysis of wood charcoal. In: Proximate analysis of biomass. USA: ASTM; 2007. p. 2.

40. Bagreev A, Bandosz TJ, Locke DC. Pore structure and surface chemistry of adsorbents obtained by pyrolysis of sewage sludge-derived fertilizer. Carbon 2001;39:1971-1979.

41. Brunauer S, Emmett PH, Teller E. Adsorption of Gases in Multimolecular Layers. J. Am. Chem. Soc. 1938;60:309-319.

42. Dehkhoda AM, Ellis N, Gyenge E. Effect of activated biochar porous structure on the capacitive deionization of $\mathrm{NaCl}$ and ZnCl2 solutions. Micropor. Mesopor. Mater. 2016;224:217-228.

43. Richards BK, Cummings RJ, White TE, Jewell W. Methods for kinetic analysis of methane fermentation in high solids biomass digester. Biomass Bioenergy. 1991;1:10.

44. Bensmann A, Hanke-Rauschenbach R, Heyer R, et al. Diagnostic concept for dynamically operated biogas production plants. Renew. Energ. 2016;96:479-489.

45. Mana H. Automatische Flow Injection Analysis-Verfahren für die Lebensmittel-, Umwelt- und klinische Analytik [Thesis]. Halle-Wittenberg: Martin-Luther-Universität Halle-Wittenberg; 1998.

46. Meseguer-Lloret S, Molins-Legua C, Campins-Falco P. Ammonium determination in water samples by using OPA-NAC reagent: A comparative study with Nessler and ammonium selective electrode methods. Int. J. Environ. Anal. Chem. 2002;82:15.

47. Caporaso JG, Lauber CL, Walters WA, et al. Global patterns of 16S rRNA diversity at a depth of millions of sequences per sample. Proc. Natl. Acad. Sci. U.S.A. 2011;108:7.

48. Hupfauf S, Etemadi M, Fernández-Delgado Juárez M, Gómez-Brandón M, Insam H, Podmirseg SM. CoMA - an intuitive and user-friendly pipeline for amplicon-sequencing data analysis. PLOS One. 2020;15:e0243241.

49. ter Braak CJF and Smilauer P. Canoco reference manual and user's guide: software for ordination, version 5.0. Ithaca: Microcomputer Power; 2012.

50. Shen Y, Forrester S, Koval J, Urgun-Demirtas M. Yearlong semi-continuous operation of thermophilic two-stage anaerobic digesters amended with biochar for enhanced biomethane production. J. Clean. Prod. 2017;167:863-874.

51. Gao F, Li Y, Bian Z, Hu J, Liu H. Dynamic hydrophobic hindrance effect of zeolite@zeolitic imidazolate framework composites for $\mathrm{CO} 2$ capture in the presence of water. J. Mater. Chem. A. 2015;3:8091-8097.

52. Gray M, Johnson MG, Dragila MI, Kleber M. Water uptake in biochars: The roles of porosity and hydrophobicity. Biomass Bioenergy. 2014;61:196-205.

53. Kim P, Johnson A, Edmunds CW, et al. Surface Functionality and Carbon Structures in Lignocellulosic-Derived Biochars Produced by Fast Pyrolysis. Energy Fuels. 2011;25:4693-4703.

54. Brewer CE, Schmidt-Rohr K, Satrio JA, Brown RC. Characterization of biochar from fast pyrolysis and gasification systems. Environ. Prog. Sust. Energ. 2009;28:386-396.
55. Rafiq MK, Bachmann RT, Rafiq MT, Shang Z, Joseph S, Long $\mathrm{R}$. Influence of pyrolysis temperature on physico-chemical properties of corn stover (Zea mays L.) biochar and feasibility for carbon capture and energy balance. PLOS One. 2016;11:17.

56. Lopez RJ, Higgins SR, Pagaling E, Yan T, Cooney MJ. High rate anaerobic digestion of wastewater separated from grease trap waste. Renew. Energ. 2014;62:234-242.

57. Ahmad M, Rajapaksha AU, Lim JE, et al. Biochar as a sorbent for contaminant management in soil and water: a review. Chemosphere 2014;99:19-33.

58. Fortuny M, Baeza JA, Gamisans X, et al. Biological sweetening of energy gases mimics in biotrickling filters. Chemosphere 2008;71:10-17.

59. Pokorna-Krayzelova L, Mampaey KE, Vannecke TP, Bartacek J, Jenicek P, Volcke EI. Model-based optimization of microaeration for biogas desulfurization in UASB reactors. Biochem. Eng. J. 2017;125:171-179.

60. Shen Y, Linville JL, Urgun-Demirtas M, Schoene RP, Snyder SW. Producing pipeline-quality biomethane via anaerobic digestion of sludge amended with corn stover biochar with in-situ CO2 removal. Appl. Energ. 2015;158:300-309.

61. Giwa AS, Xu H, Chang F, et al. Effect of biochar on reactor performance and methane generation during the anaerobic digestion of food waste treatment at long-run operations. J. Environ. Chem. Eng. 2019;7:103067.

62. Kizito S, Wu S, Kirui WK, et al. Evaluation of slow pyrolyzed wood and rice husks biochar for adsorption of ammonium nitrogen from piggery manure anaerobic digestate slurry. Sci. Total Environ. 2015;505:102-112.

63. Kizito S, Wu S, Wandera SM, Guo L, Dong R. Evaluation of ammonium adsorption in biochar-fixed beds for treatment of anaerobically digested swine slurry: experimental optimization and modeling. Sci. Total Environ. 2016;563:1095-1104.

64. Sinervo R. Effects of biochar addition on anaerobic digestion and comparison of different biochar qualities. Master Thesis. University of Jyväskylä, Department of Biological and Environmental Sciences. Finland. 2017.

65. Poirier S, Desmond-Le Quéméner E, Madigou C, Bouchez T, Chapleur O. Anaerobic digestion of biowaste under extreme ammonia concentration: identification of key microbial phylotypes. Bioresour. Technol. 2016;207:92-101.

66. Ma H, Hu Y, Kobayashi T, Xu K-Q. The role of rice husk biochar addition in anaerobic digestion for sweet sorghum under high loading condition. Biotechnol. Rep. 2020;e00515.

67. Lv Z, Chen Z, Chen X, Liang J, Jiang J, Loake GJ. Effects of various feedstocks on isotope fractionation of biogas and microbial community structure during anaerobic digestion. Waste Manage. 2019;84:211-219.

68. Liu Y, Wachemo AC, Yuan H, Li X. Anaerobic digestion performance and microbial community structure of corn stover in three-stage continuously stirred tank reactors. Bioresour. Technol. 2019;287:121339.

69. Suksong W, Tukanghan W, Promnuan K, et al. Biogas production from palm oil mill effluent and empty fruit bunches by coupled liquid and solid-state anaerobic digestion. Bioresour. Technol. 2020;296:122304.

70. Alsaker KV, Paredes C, Papoutsakis ET. Metabolite stress and 
tolerance in the production of biofuels and chemicals: gene-expression-based systems analysis of butanol, butyrate, and acetate stresses in the anaerobe Clostridium acetobutylicum. Biotechnol. Bioeng. 2010;105:1131-1147.

71. Shamurad B, Sallis P, Petropoulos E, et al. Stable biogas production from single-stage anaerobic digestion of food waste. Appl. Energ. 2020;263:114609.

72. Su X-L, Tian Q, Zhang J, et al. Acetobacteroides hydrogenigenes gen. nov., sp. nov., an anaerobic hydrogen-producing bacterium in the family Rikenellaceae isolated from a reed swamp. Int. J. Syst. Evol. Microbiol. 2014;64:2986-2991.

73. Nakasaki K, Nguyen KK, Ballesteros Jr FC, Maekawa T, Koyama M. Characterizing the microbial community involved in anaerobic digestion of lipid-rich wastewater to produce methane gas. Anaerobe 2020;61:102082.

74. Hahnke S, Langer T, Koeck DE, Klocke M. Description of Proteiniphilum saccharofermentans sp. nov., Petrimonas mucosa sp. nov. and Fermentimonas caenicola gen. nov., sp. nov., isolated from mesophilic laboratory-scale biogas reactors, and emended description of the genus Proteiniphilum. Int. J. Syst. Evol. Microbiol. 2016;66:1466-1475.

75. Alauzet C, Marchandin H, Courtin P, et al. Multilocus analysis reveals diversity in the genus Tissierella: description of Tissierella carlieri sp. nov. in the new class Tissierellia classis nov. Syst. Appl. Microbiol. 2014;37:23-34.

76. Lawson PA. T issierella. Bergey's Man. System. Arch. Bact. 2019;1-12.

77. Dong L, Cao G, Tian Y, et al. Improvement of biogas production in plug flow reactor using biogas slurry pretreated cornstalk. Bioresour. Technol. Rep. 2020;9:100378.

78. Regueiro L, Carballa M, Lema JM. Outlining microbial community dynamics during temperature drop and subsequent recovery period in anaerobic co-digestion systems. J. Biotechnol. 2014;192:179-186.

79. Wang H, Zhu X, Yan Q, Zhang Y, Angelidaki I. Microbial community response to ammonia levels in hydrogen assisted biogas production and upgrading process. Bioresour. Technol. 2020;296:122276.

80. Rajendran K, Mahapatra D, Venkatraman AV, Muthuswamy S, Pugazhendhi A. Advancing anaerobic digestion through two-stage processes: Current developments and future trends. Renew. Sust. Energ. Rev. 2020;123:109746.

81. Supaphol S, Jenkins SN, Intomo P, Waite IS, O’Donnell AG. Microbial community dynamics in mesophilic anaerobic co-digestion of mixed waste. Bioresour. Technol. 2011;102:4021-4027.

82. Zhang Q, Wang M, Ma X, et al. High variations of methanogenic microorganisms drive full-scale anaerobic digestion process. Environ. Int. 2019;126:543-551.

83. Zeng Y, Luo Y, Huan C, et al. Anoxic biodesulfurization using biogas digestion slurry in biotrickling filters. J. Clean. Prod. 2019;224:88-99.

84. Díaz AI, Oulego P, Collado S, Laca A, González JM, Díaz M. Impact of anaerobic digestion and centrifugation/decanting processes in bacterial communities fractions. J. Biosci. Bioeng. 2018;126:742-749.

85. Liu P, Klose M, Conrad R. Temperature effects on structure and function of the methanogenic microbial communities in two paddy soils and one desert soil. Soil Biol. Biochem. 2018;124:236-244.

86. Peng J, Wegner C-E, Bei Q, Liu P, Liesack W. Metatranscriptomics reveals a differential temperature effect on the structural and functional organization of the anaerobic food web in rice field soil. Microbiome 2018;6:1-16.

87. Noll M, Klose M, Conrad R. Effect of temperature change on the composition of the bacterial and archaeal community potentially involved in the turnover of acetate and propionate in methanogenic rice field soil. FEMS Microbiol. Ecol. 2010;73: 215-225.

88. Jiang Y, Banks C, Zhang Y, Heaven S, Longhurst P. Quantifying the percentage of methane formation via acetoclastic and syntrophic acetate oxidation pathways in anaerobic digesters. Waste Manage. 2018;71:749-756.

89. Luo C, Lü F, Shao L, He P. Application of eco-compatible biochar in anaerobic digestion to relieve acid stress and promote the selective colonization of functional microbes. Water Res. 2015;68:710-718.

90. Ho D, Jensen P, Batstone D. Effects of temperature and hydraulic retention time on acetotrophic pathways and performance in high-rate sludge digestion. Environ. Sci. Technol. 2014;48: 6468-6476. 